\title{
Learning Challenges During Pandemic Situation: Lithuanian University Case
}

\author{
(D)Nijolė Petkevičiūtė ${ }^{1}$ Dr.; (D)Asta Balčiūnaitienė ${ }^{2}$ Dr. \\ Vytautas Magnus university, Lithuania \\ Nijole.Petkeviciute@vdu.1t ${ }^{1}$; Asta.Balciunaitiene@vdu.1t²
}

\begin{abstract}
Learning issues in the context of the pandemic situation will be discussed in the paper. Research problem - learners lack relevant information, knowledge and skills about creativity for adequate problem solving. Distant learning requires to create environment suitable for students' needs in the case of a critical situation (for example, Covid 19 pandemic). It motivates students to change their attitudes and behaviours while combining different actions based on their self-awareness and creativity. Therefore, students need to develop their creativity skills to facilitating problem solving. Moreover, it is significant to raise students understanding about themselves to make adequate decisions for efficient learning during the lockdown because of Covid-19 pandemic. The aim of the research is to find out and discuss students' learning difficulties and experiences during a pandemic, and to find out how creativity can contribute to problem-solving. For this reason, it is essential that learners concentrate on how to develop their creativity for better learning in uncertainty conditions. Used research methods were scientific literature analysis, quantitative (questionnaire) study and descriptive analysis. The findings of the study demonstrate that learners have major distant learning difficulties and various social psychological problems during the pandemic situation in Lithuania. Moreover, the results show that learners lack understanding about the importance of knowledge and opportunities for creative problem solving during distant learning processes in the pandemic situation.
\end{abstract}

Keywords: university education, pandemic situation, learning, challenges, creativity, problem-solving.

\section{Introduction}

A pandemic is an epidemic that has spread over multiple countries and continents. The disease was first identified in December 2019 in Wuhan, China. The outbreak was declared a Public Health Emergency of International Concern by the World Health Organisation (WHO) in January 2020, and was recognised as a pandemic in March 2020. COVID-19 has affected day-to-day life, businesses, education and disrupted world trade and movements. The COVID-19 pandemic has a big impact on the learning outcomes of education systems across world, which affects all learners, teachers, although in differing degrees depending on multiple factors - including the country/region where they live, as well as their age, family background and the degree of access to some "substitute" educational opportunities. School closure is systematically associated with the development of problems involving students, teachers and parents, particularly among populations with poor resources. Unfortunately, there are not yet convincing scientific evidence that school closure would provide real effectiveness in controlling a pandemic (Esposito, Cotugno, Principi, 2021). In spite of that, in many countries, educational institutions have moved to work remotely for health security purposes, which means rapid digitalisation of the learning process.

However, it is not easy to digitalize learning processes, but it opens up new learning horizons and challenges providing students with learning from anywhere they have access to the Internet, as well as learning at their convenience. Digitalization offers tremendous opportunities for innovation, growth and employment, contributes to the global competitiveness of people and enhances creativity and cultural diversity (Visvizi, Lytras, Daniela, 2018). The digitalization and the digital transformation of education stimulated by it increasingly influence the development of the education system including the learning process of individuals, which poses new challenges and tasks. O. Vindaca and V. Lubkina (2020) worked out the concept of transformative digital learning - the process of individualized, lifelong spontaneous or planned technology - enhanced learning, changing and updating of educational results, content, methods and organizational forms adopting them to the quickly evolving digital environment, including physical and philosophical change or transformation to meet growing demands of learners to achieve rich intellectual property by defining new perspectives and adopting personal worldview accordingly value - created learning. Transformative digital learning is associated with qualitative changes in educational work, especially in higher education. 
However, during the first pandemic wave, all learners lacked daily access to their basic educational institution's provisions, they also lost group activities, relationships, social links and other face-to-face possibilities. It goes without saying that the education system was not ready to cope with a situation like this as it lacked experience, knowledge and structure to sustain and to provide the necessary web-based learning safety for more effective teaching and learning processes.

Although academics are known for their resilience and ability to adapt to changing circumstances, the pandemic caused additional concerns and suffering for both students and academic staff, especially regarding internships when it was transferred or cancelled. Some teachers have successfully adapted, while others are still trying to adapt and looking for solutions to ensure adequate teaching quality in the face of Covid-19 uncertainty (Jung, Horta, Postiglione, 2021).

Furthermore, as the structure of readiness for professional activities is formed of two basic components - psychological readiness and competence-based readiness, the school needs educators, who are aware of the teacher's mission under the changing circumstances nowadays (Baltusite, Katane, 2014). Therefore, the need for educators to adapt quickly to the changes caused by a pandemic, to be prepared to work remotely, to use both their psychological resilience and to make full use of their pedagogical competencies is essential. Moreover, one of the pedagogical competences is teachers' verbal creativity, what includes all features of its expression - creative fluency, flexibility and originality. That is why any change begins with the teachers' personality, knowledge, experience and skills (Valantinaite, Sederevičiūte-Pačiauskiené, Dislere, 2016). In these pandemic conditions, educators need to be particularly flexible, to be able to adapt quickly to new circumstances, to find creative solutions to teaching materials, and rapidly develop verbal creativity for learning in a remote environment.

The current lockdown is unique, and in most ways, it is much more severe than any other crisis we have experienced in recent history. Almost overnight, the pandemic forced the cancellation of the traditional learning that occurs in university and school settings. The pandemic has affected inputs at home as family and community health and work crises are less able to provide supports for learning at home. Due to the fact that there are no direct comparisons to past events or trends, we are without fully valid references for assessing the likely impacts of the COVID-19 crisis on learners. There are, however, specific aspects of this crisis that have arisen in other contexts and been studied by education researchers, and we can derive from them some guidance on topics such as the loss of learning time and use of innovative learning methods (García, Wiss, 2020).

The 2020-2021 academic year is now underway with many universities remaining physically closed as the 2021 year begins, there is more need to understand and think through if we are ready to meet the crisis head-on. If teachers are expected to do their jobs effectively during the pandemic, and if our education system has to achieve the goals of excellence and equity in the later stages of a pandemic, it will be critical to support students who learn a lot and struggle for their own development, learning what problems prevent teachers from teaching these students and what efforts it is needed to make to address these problems (García, Wiss, 2020). As this pandemic has affected thousands of people in various fields such as health care, economic, social and everyday life. Quarantine and treatment of suspected or confirmed cases were a big challenge for health care. Overload on doctors and other healthcare professionals, who are at a very high risk and disruption of a medical supply chain. Economics: recession of manufacturing, disconnection of the supply chain of products, losses in national and international businesses, poor money flow in the market, significant slowing down in revenue growth. Moreover, the social service sector is lagging behind to provide proper services, cancellation or postponement of large-scale sports and tournaments, avoiding national and international travelling, cancellation of celebration of cultural, religious festivals, closure of places for entertainment such as cinemas, theatres, sports clubs, swimming pools as well as the requirements for social distancing with family members, friends, colleagues and neighbours. All these changes increase anxiety among the population in everyday life, but especially in learning and working environments. However, looking at the learning challenges during the pandemic situation, it could be outlined both sides of the coin - positive and negative (Haleem, Javaid, Vaishya, 2020).

The positive side of this situation is that people spend more time with their families, pay more attention to their wellbeing, emotional, mental and physical health. They started to take up new hobbies - yoga, meditation, self-learning and self-observation exercises. 
Unfortunately, there's a negative side of this pandemic situation which greatly affects people's mental, psychological and physical health. People do not have face-to-face communication and relationship they do not socialize with their colleagues, groupmates and friends. Therefore, due to less face-to-face communication, social media, such as video calling, chat, movies, music and new apps, are gaining its popularity at a fast speed, making people spend nearly all day switching on various technical devices. This digitalized lifestyle adds to the increased addiction to mobile phones and the Internet, followed by anxiety, restlessness, insomnia, bad temper, confusion and even depression. Educators must urgently look at some learning challenges such as lack of motivation, self-discipline, creativity and productive problem-solving skills as well as not having internet connections that appear most pertinent to the current crisis. Moreover, the study results are only partially applicable to the learning situations arising during this pandemic, but we believe it can help guide how to improve learning and how to uplift learners' recovery into their normal mode of operation in the future. V. Dislere and N. Vronska pay attention to the activities of career consultants both in schools and universities. Career counsellors help students to develop their personality and solve problems, as well as to make informed decisions (Dislere, Vronska, 2020). The authors acknowledge that in the conditions of a pandemic, it would be useful to attract career counsellors to help students cope with the non-standard situation, not to lose focus and not to get depressed. Dealing with the problems caused by the pandemic it must be borne in mind that the world is changing and that these processes are not explicit in our daily lives, studies and work. For this reason, we are working and learning in the uncertainty environment, it is necessary to pay more attention to personal creativity for promoting problem solving.

Creative learning outcomes can be supported through a self-directed learning process, where teachers can support learners in this process in three different ways - experiential learning, workplace simulations and problem-solving in case studies (Morris, 2020). Creativity is the attitude, the tendency to generate or recognize ideas, possibilities that could be useful in productive problem solving. It helps to think about a problem in the new way; using the imagination to create new ideas. Five main components of creativity could be developed - creative thinking, knowledge, technical skills, intellectual power, and intrinsic and extrinsic motivation (Germer, Siegel, Fulton, 2013). By deliberately applying the findings of the above-mentioned scientists, the difficulties caused by a pandemic would be easier to overcome.

Furthermore, for productive problem solving some other skills are needed, such as: creativity, emotional intelligence, research, risk management and decision-making skills. In times when a decision could be made quickly, it depends on themselves to think outside the box to find the best result of problem solving. Creativity is deeply connected with intuition, so sometimes the problem could be solved in a short way, when one's had enough knowledge about values (Racene, Dislere, 2019; Ivanova, Ignatjeva, 2018). However, in the case of pandemic people did not have enough information and experience before, so usage of more systematic and logical point of view and potential of creativity are needed. Problem solving in the pandemic situation deeply depends on individual psychological capital - positive psychological state. According to some researchers (Youssef-Morgan, Luthans, 2013) psychological capital consists of hope, self-efficacy, resilience and optimism. The nature of creativity from the point of view of thinking stems from the specifics of the mechanisms of reflection - in thinking as a process of self-research, attention is focused on the meaningful activity of consciousness; creativity depends on how the world is perceived, on the knowledge of ideal images in any field which are formed through reflection (Borovinskaya, Surovtsev, 2019). Thereby, students can do a lot for themselves to cope with the pandemic situation, use intuition, self-study and stabilize their mental states with conscious positive thinking and self-directed learning, all of which lead to self-efficacy.

Self-regulation skills regarding the usage of an online learning environment have been considered as fundamental skills for effective decision making (Çevik et al., 2020).

There could be used useful technics for creative problem solving, such as: mind mapping, brainstorming and PERMA (Positive, Engagement, Relationships, Meaning, Achievement) model. It would be very useful for students to apply the PERMA model developed by M.E.P. Seligman (2011), which stands for the five parameters that should be used as a vision for experienced lasting wellbeing. These parameters are: positive emotion; engagement; positive relationships; meaning; achievement. During pandemic it is important for students and all surrounding people to develop and share positive emotions and feelings. Positive Emotions (P) such as: pleasure, inspiration, love, satisfaction, hope, gratitude, peace and curiosity are important for the self-enjoyment of the activities what person are involved here and now. Involvement (E) could be 
described as a person experiencing a state of flow: time seems to stop, there is a feeling of loss of self-esteem and an intense focus on the present. The more a person experiences this type of engagement, the more likely they are to be satisfied with well-being, even in critical situations. Positive Relationships (R) are crucial for humans as "social beings". Polite and emphatic relationships are core elements to person's achievement and prosperity. Meaning (M) that is true that we all need meaningful fulfilment in our lives to have a sense of satisfaction what we are doing in critical situations. Meaning (M) comes from serving a cause bigger than ourselves. Achievement (A) is a valuable attribute when we are seeking to master a skill, achieve a valuable goal and win life's victory. It could be stated that the PERMA model could be a good instrument for all learners and teachers to develop their skills of creativity and problem solving.

The aim of the research is to find out and discuss students' learning difficulties and experiences during a pandemic, and to find out how creativity can contribute to problem-solving.

\section{Methodology}

To analyse student' learning experiences, a quantitative study (questionnaire) was designed by the authors and 95 students took part in the research and answered the questionnaire expressing their opinions about arising difficulties and experiences.

In this article, two research questions were put forward:

- what were the students' learning difficulties and experiences during the pandemic;

- how creativity can contribute to problem-solving.

The results were processed by using MS Excel and descriptive analysis.

Quantitative research method enables to collect information about students' learning issues during pandemic quarantine and helps to discover original facts which are useful for interpretation and discussion. In the scientific field (DeFranzo, 2011; McLeod, 2019; Muijs, 2010) there are mentioned some methods about quantitative information gathering: various forms of survey (internet, paper, mobile studies, conversations and examination through phone); systematic observations (DeFranzo, 2011); experimental methods (McLeod, 2019). S.E. DeFranzo (2011) emphasizes that the quantitative method of data collection is more structured than qualitative method because quantitative method is related with numbers, logic and objective attitude. This method is applied to construe a phenomenon to understand problems and reveal causes at the same time used for scientific discussion. The quantitative method (questionnaire) of the study was applied to determine respondents' experiences during the pandemic situation. The questionnaire was organized in a particular environment (university) with the aim to investigate students' experiences, arising problems during pandemic situations and to analyse their main challenges for problem solving. Investigating students' experiences during the pandemic situation the questionnaire of ten questions was designed. The respondents were asked questions about their experience and learning problems during the first pandemic situation in Lithuania. There were closed and open questions and some statements. Questionnaires were anonymous, the answers were marked by minus or plus, or underlined. The questions in the questionnaire were constructed to collect information about students' experiences and attitudes during the pandemic situation.

Respondents. Quantitative research was performed in May 2020. There were 95 students who answered the questionnaire which was designed by the authors in English. The respondents were from Lithuania, Spain, Russia, China, Egypt, Kazakhstan, Belorus, Nigeria and Ghana. The majority of the respondents were from various faculties in Bachelor and Master levels of education and studied English in different levels: A1, A2, B1, B2, C1, C2, because it is obligatory to achieve C1 and C2 levels of English at Vytautas Magnus university in Kaunas, Lithuania. Students' knowledge in English played a significant role, because they were from different countries and various systems of education. The distribution of the respondents according the level of education and achieved level of English is demonstrated in Figure 1. Students who took part in the research were mostly of the Bachelor education level (96.5\%) and some of the Master level of education (3.5\%). The majority of students who achieved B2 level were Bachelor level students of education - B2 (53.7 \%), A1 - A2 (32\%); less - B1 (10,8 \%). Master level students achieved - C1 (3.0\%), C2 (0.5\%) English level (Figure 1). 


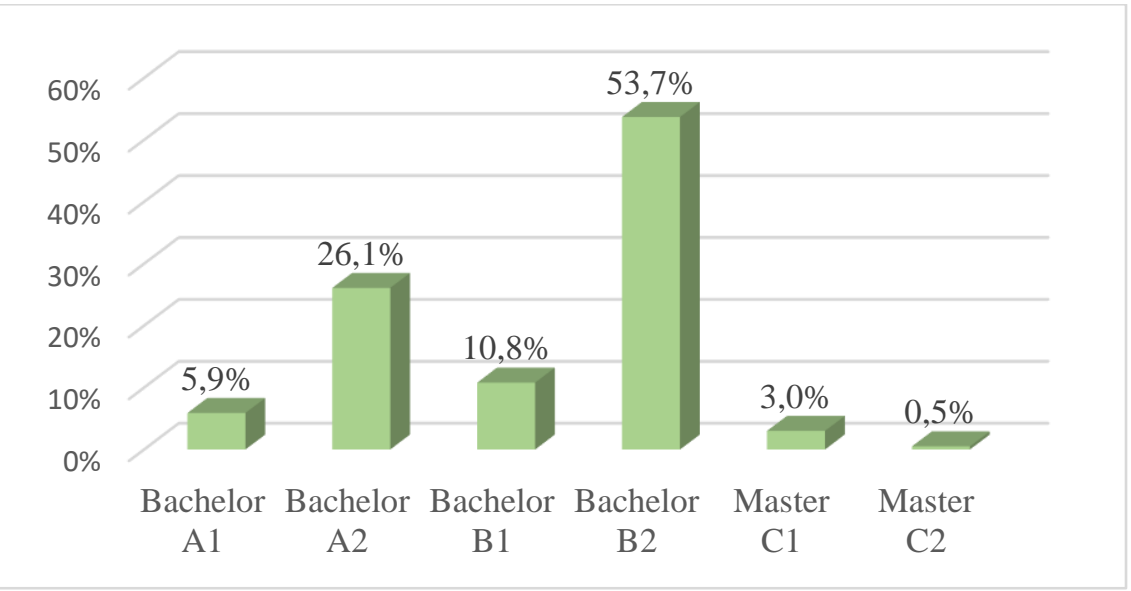

Figure 1. Distribution of respondents according level of education and achieved

$$
\text { A1 - C2 level of English. }
$$

At the same time in an English class there were students from Bachelor and Master programmes. As the respondents were asked to answer the questions in English, it can be stated that they were able to understand and give adequate answers. For foreign students who studied at Vytautas Magnus University during the pandemic, English language skills were important to be able to follow the study process in a remote version. It was an additional challenge to continue their studies without meeting the lecturers in person.

\section{Results and Discussions}

The study revealed that $67.6 \%$ of respondents had difficulties in distance learning and $27.6 \%$ of respondents did not have any distance learning difficulties during quarantine in Lithuania. The study results showed that respondents had distance learning and personal problems arising during the lockdown which they have to cope with and solve (Figure 2).

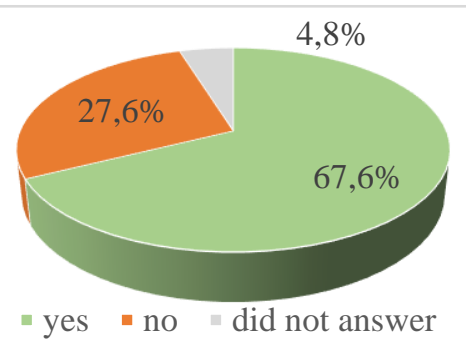

Figure 2. Students' opinions on whether they had difficulties in distance learning during quarantine in Lithuania.

The study demonstrated that the respondents not only have had some learning problems, but also, they have faced psychological, emotional and social problems as well. The respondents marked that they did not have enough knowledge, skills and competence how to deal with those problems. The respondents indicated the most worrying problems "Increased nervousness and anger attacks" (11.4\%), "Increased anxiety and fear" (28.6\%); "Unwillingness to act " $(1.4 \%)$, on the other hand quite a lot of respondents did not have any problems (42.9\%) (Table 1$)$.

Table 1

The distribution of students' opinions about psychological problems during quarantine (\%)

\begin{tabular}{|c|l|c|}
\hline No & \multicolumn{1}{|c|}{ Mentioned psychological problems } & $\mathbf{\%}$ \\
\hline 1 & Increase nervousness, anger attacks & 17.1 \\
\hline 2 & Increased anxiety, fear & 28.6 \\
\hline 3 & Unwillingness to act & 11.4 \\
\hline 4 & No problems & 42.9 \\
\hline
\end{tabular}


The respondents expressed their optimistic attitude, too. The students indicated the positive features of pandemic situation. The most common answers were:

- "people have more free time to take up new hobbies";

- "people have more free time for learning new things and gaining new skills";

- "when pandemic situation is over people will have better skills to study online which is money saving".

The respondents' positive attitude to the pandemic situation shows that they are trying to use creativity "for learning new things and new skills". During the pandemic situation, problem solving and creativity skills development is an urgent activity, so the students were asked to express their opinions about creativity for problem solving, which is essential during pandemic situation. The analysis of percentage distribution of students' answers demonstrated that the majority of respondents (45.9\%) have some trouble demonstrating new ideas in a creative way (Table 2).

Table 2

The distribution of students' opinions about creativity (\%)

\begin{tabular}{|c|l|c|c|c|c|c|}
\hline No & \multicolumn{1}{|c|}{ Statements } & $\begin{array}{c}\text { Totally } \\
\text { disagree }\end{array}$ & Disagree & $\begin{array}{c}\text { Neither agree } \\
\text { nor disagree }\end{array}$ & $\begin{array}{c}\text { Agree } \\
\text { Totally } \\
\text { agree }\end{array}$ \\
\hline 1 & Teachers value learners' creativity & 0.0 & 0.5 & 20.0 & 55.0 & 15.5 \\
\hline 2 & Creativity is a value & 0.0 & 1.0 & 20.4 & 63.5 & 15.1 \\
\hline 3 & $\begin{array}{l}\text { There are good conditions for the } \\
\text { development of creativity in learning } \\
\text { environment }\end{array}$ & 1.5 & 1.2 & 32.1 & 58.1 & 7.1 \\
\hline 4 & $\begin{array}{l}\text { Students have problems demon- } \\
\text { strating new ideas in a creative way }\end{array}$ & 19.9 & 10.6 & 20.1 & 45.9 & 3.5 \\
\hline
\end{tabular}

Therefore, it could be stated that education institutions should offer more favourable learning environment to develop creativity skills as most respondents agree that creativity competence is greatly valued as well as that there are opportunities and conditions at university for students of different programs to be more creative. Consequently, it might be assumed that the development of creativity is as one of the most valuable instruments for problem solving (Germer, Siegel, Fulton, 2013).

However, some respondents did not express their opinions, so it was not clear if they agree or disagree about the importance of creativity. For example, the statement that there are good conditions to be creative nearly one-third of the respondents $(32.1 \%)$ did not indicate their options. This tendency could be interpreted as learners are still unfamiliar with creativity skills importance and therefore pay little attention to the development of creativity skills during their studies at university. Moreover, the concept of creativity must have been misinterpreted and could have been understood as artistic activities, but not as diverse, non-standard, inclined to innovation way of thinking.

The study results reveal that during the pandemic situation students identify both positive and negative sides of the processes trying to find a certain balance and harmony. Facing uncertainty and disbalance in the lockdown, they are looking for positive ways how to solve their learning problems. Most of the respondents struggled to seek for their inner potential. They characterised this pandemic situation as a period of better self-understanding, the quest for meaning, as well as the search of self in a real environment. They stressed the importance of the learning process itself and the understanding of oneself in the context of lockdown.

\section{Conclusions}

The study results revealed that respondents had distant learning problems arising during the lockdown which they have to cope with and solve. The study about students' experience during Covid 19 pandemic in Lithuania demonstrated that their experiences during these periods were changes of the learning process; psychological problems; lack of knowledge and skills for creative problem solving. It is essential for learners to perceive the scale of problems so they could be able to choose creativity instruments for their problem solving. 
The study results revealed that during the pandemic situation students identified positive sides of the distant learning processes trying to find their potential for creativity. While encountering anxiety, stress, uncertainty and disbalance, they are looking for optimistic and creative ways how to solve their problems.

The findings demonstrated that learners have to solve arising problems instantly, and they need to develop problem solving skills. For this reason, it is important to mention that learners must have more theoretical and practical information about problem solving in critical situations.

The study demonstrated that the respondents had learning problems and the changes during quarantine have troubled them. Moreover, the study results revealed that the respondents have faced other problems too, such as psychological - nervousness, anger attacks; emotional - sadness, anxiety and social unwillingness to socialize and act which most worried them. What is more, the respondents marked that they did not have enough knowledge, skills and competence how to deal with those problems.

During the pandemic situation and in any crisis, the development of problem solving and creativity skills is an urgent activity. Therefore, the respondents were asked to express their opinions about creativity for problem solving. The analysis of the percentage distribution of students' answers demonstrated that the majority of respondents $(45,9 \%)$ have some problems demonstrating new ideas in a creative way, therefore, the authors recommend more use of self-expression, which includes creative fluency, flexibility and self-discipline, to develop productive problem-solving skills searching for original problem-solving ways. The results of the study showed that the respondents also marked a positive side of quarantine as they had more free time for learning new things, gaining new skills and taking up new hobbies.

\section{Bibliography}

1. Baltusite R., Katane I. (2014). The Structural Model of the Pedagogy Students' Readiness for Professional Activities in the Educational Environment. In V. Dislere (Ed.), The Proceedings of the International Scientific Conference Rural Environment. Education. Personality (REEP), 7. Jelgava: LLU, 29-41. Retrieved from https://llufb.llu.lv/conference/REEP/2014/Latvia-Univ-AgricultREEP-2014proceedings-29-41.pdf

2. Borovinskaya D.N., Surovtsev V.A. (2019). Reflection and the nature of creativity. Vestnik Tomskogo Gosudarstvennogo Universiteta - Filosofiya - Sotsiologiya - Politologiya - Tomsk State University Journal of Philosophy Sociology and Political Science, 49, 17-25. Retrieved from http://journals.tsu.ru/uploads/import/1838/files/1998-863X_i49_p017.pdf

3. Çevik Y.D., Dağhan G., Somyürek S., Mumcu F. (2020). Reflections on the Implementation an Online Learning Environment Designed to Improve Students' Decision-Making Skills. In L.G. Chova, A.L. Martinez., I.C. Torres (Eds)., Proceedings of the Conference International Technology, Education and Development (INTED2020), 14, 5313-5322. doi: 10.21125/inted.2020.1438

4. DeFranzo S.E. (2011). What's the difference between qualitative and quantitative research? Retrieved from https://www.snapsurveys.com/blog/qualitative-vs-quantitative-research

5. Dislere V., Vronska N. (2020). Evaluation of Career Counsellors' Competences in Career Guidance. In V. Dislere (Ed.), The Proceedings of the International Scientific Conference Rural Environment. Education. Personality (REEP), 13. Jelgava: Latvia University of Life Sciences and Technologies, 385-399. doi: 10.22616/REEP.2020.046

6. Esposito S., Cotugno N., Principi N. (2021). Comprehensive and safe school strategy during COVID-19 pandemic. Italian Journal of Pediatrics, 47, 6. doi: 10.1186/s13052-021-00960-6

7. García E., Wiss E. (2020). COVID-19 and student performance, equity, and U.S. education policy. Lessons from pre-pandemic research to inform relief, recovery, and rebuilding. Retrieved from https://epi.org/205622

8. Germer C.K., Siegel R.D., Fulton P.R. (Eds.). (2013). Mindfulness and Psychotherapy (2 ${ }^{\text {nd }}$ ed.). New York, NY: Guilford Press.

9. Haleem A., Javaid M., Vaishya R. (2020). Effects of COVID-19 pandemic in daily life. Current medicine research and practice, 10(2), 78-79. doi: 10.1016/j.cmrp.2020.03.011

10. Ivanova M., Ignatjeva S. (2018). Harmonization of Organizational Culture Values and Personal Values in Public Sector. In V. Dislere (Ed.), The Proceedings of the International Scientific 
Conference Rural Environment. Education. Personality (REEP), 11. Jelgava: Latvia University of Life Sciences and Technologies, 364-372. doi: 10.22616/REEP.2018.044

11. Jung J., Horta H., Postiglione G.A. (2021). Living in uncertainty: the COVID-19 pandemic and higher education in Hong Kong. Studies in Higher Education, 46(1), 107-120. doi: 10.1080/03075079.2020.1859685

12. McLeod S.A. (2019). What's the difference between qualitative and quantitative research? Retrieved from: https://www.simplypsychology.org/qualitative-quantitative.html

13. Morris T.H. (2020). Creativity through self-directed learning: three distinct dimensions of teacher support. International Journal of Lifelong Education, 39(2), 168-178. doi: 10.1080/02601370.2020.1727577

14. Muijs D. (2010). Doing Quantitative Research in Education with SPSS (2 ${ }^{\text {nd }}$ ed.). London: Sage Publications. doi: 10.4135/9781849203241

15. Racene A., Dislere V. (2019). Choice of a Value Identification Method in Career Counselling. In V. Dislere (Ed.), The Proceedings of the International Scientific Conference Rural Environment. Education. Personality (REEP), 12. Jelgava: Latvia University of Life Sciences and Technologies, 289-296. doi: 10.22616/REEP.2019.038

16. Seligman M.E.P. (2011). Flourish: A Visionary New Understanding of Happiness and Well Being. Free Press.

17. Valantinaitè I., Sederevičiūtè-Pačiauskienė Ž., Dislere V. (2016). Dimension of Consumer Culture in Verbal Creativity expression of Pre-service Technology Teachers in the Baltic Countries: the Field of Electronics. In V. Dislere (Ed.), The Proceedings of the International Scientific Conference Rural Environment. Education. Personality (REEP), 9. Jelgava: LLU, 174-186. Retrieved from https://llufb.llu.lv/conference/REEP/2016/Latvia-Univ-Agricult-REEP-2016proceed2255-808X-174-186.pdf

18. Vindaca O., Lubkina V. (2020). Transformative Digital Learning in the Context of Higher Education: Definition and Basic Concepts. In V. Dislere (Ed.), The Proceedings of the International Scientific Conference Rural Environment. Education. Personality (REEP), 13. Jelgava: LLU, 177-184. doi: 10.22616/REEP.2020.021

19. Visvizi A., Lytras M.D., Daniela L. (Eds.). (2018). The Future of Innovation and Technology in Education: Policies and Practices for Teaching and Learning Excellence. UK, North America, Japan, India, Malasia, China: Emerald Publishing.

20. Youssef-Morgan C.M., Luthans F. (2013). Psychological capital theory: Toward a positive holistic model. In A.B. Bakker (Ed.), Advances in positive organizational psychology, 1. Bingley, UK: Emerald, 145-166. doi: 10.1108/S2046-410X(2013)0000001009 